\title{
Design, Synthesis and Biological Evaluation of Alkylamino Biphenylamides as Hsp90 C-Terminal Inhibitors
}

Gaurav Garg ${ }^{1,}$ Huiping Zhao ${ }^{1}$, and Brian S. J. Blagg ${ }^{1 *}$

1. Department of Medicinal Chemistry, 1251 Wescoe Hall Drive, Malott 4070, The University of Kansas, Lawrence, Kansas 66045-7563, USA

* Author to whom correspondence should be addressed. Phone: (785) 8642288. Fax: (785) 864-5326. Email: bblagg@ku.edu.

\section{Abstract}

Hsp90 is a promising therapeutic target for the development of anti-cancer agents due to its integral role in the stability and function of proteins associated with all ten hallmarks of cancer. Novobiocin, a coumarin antibiotic, was the first natural product identified that targeted the Hsp90 C-terminal domain and manifested anti-proliferative activity $\left(\mathrm{SKBr} 3 \mathrm{IC}_{50} \sim 700 \mu \mathrm{M}\right)$. Subsequent structural investigations on novobiocin led to analogues with significantly improved anti-proliferative activity against multiple cancer cell lines. In an effort to develop more efficacious and diverse analogues, it was recently found that the coumarin ring of novobiocin could be replaced with the biphenyl core without compromising activity. Based on these prior studies, a series of alkylamino biphenylamides was designed, synthesized and evaluated for antiproliferative activity against two breast cancer cell lines. SAR studies demonstrated that the incorporation of an alkylamino side chain onto the biphenyl core improved antiproliferative activity and resulted in compounds that exhibit sub-micromolar to midnanomolar activity through Hsp90 inhibition. Importantly, these studies indicate the presence of a hydrophilic region about the central core that can be exploited for the design of new inhibitors.

Keywords: Heat shock protein 90; Hsp90 C-terminal inhibitors; Alkylamino biphenylamides; Structure-activity relationship; Breast cancer. 


\section{Introduction}

Heat shock protein 90 (Hsp90) is a highly conserved molecular chaperone that plays a critical role in protein homeostasis. ${ }^{1}$ Hsp90 regulates the conformational maturation, activation and stability of more than 300 client proteins, including cytosolic signaling proteins, transcription factors, and kinases. ${ }^{2}$ Several of these clients (eg. Her2, CDK6, Raf1, Akt, survivin, telomerase) have been implicated in the development and progression of cancer and are directly associated with all ten hallmarks of cancer. $^{3-5}$ Moreover, in cancer cells, Hsp90 is overexpressed to promote cellular growth and/or survival under the hostile micro-environment characterized by proteotoxic stresses, such as imbalanced protein production, accumulation of mutated proteins, and increased protein damage due to oxidative stress. ${ }^{6,7}$ Consequently, Hsp90 has emerged as a promising target for the development of anticancer chemotherapeutics. ${ }^{8,9}$ In fact, 17 small molecules that target the Hsp90 N-terminus have been investigated in clinical trials for the treatment of various cancers, highlighting the therapeutic potential of Hsp90 inhibitors as anticancer agents. ${ }^{10}$ Although these investigational drugs have provided proof-of-concept for Hsp90 inhibitors in cancer, their clinical translation has been hampered by concomitant induction of the pro-survival heat shock response (HSR), cardiac arrhythmia and hepatotoxicity, and thus necessitate alternative methods to modulate Hsp90 for cancer treatment. $^{11,12}$

Prior studies identified small molecules that bind the Hsp90 C-terminal domain and allosterically modulate Hsp90 function. ${ }^{13-15}$ Novobiocin (1), a coumarin antibiotic, was the first natural product identified as an Hsp90 C-terminal inhibitor. ${ }^{13}$ Importantly, novobiocin did not induce the HSR, which is a major detriment resulting from Hsp90 Nterminal inhibition. Unfortunately, novobiocin exhibits poor efficacy against cancer cells (SKBr3 $\mathrm{IC}_{50} \sim 700 \mu \mathrm{M}$ ), and consequently, offers limited therapeutic potential. Recent 
studies on novobiocin led to the elucidation of some structure-activity relationships (SAR) and identified key structural elements required for Hsp90 inhibition (Figure 1). ${ }^{16-}$

${ }^{23}$ SAR studies revealed that the benzamide side chain is critical to manifest antiproliferative activity and modifications to this moiety produced molecules that exhibited increased anti-proliferative activity against multiple cancer cell lines. ${ }^{18,20-24}$ In addition, it was found that the noviose sugar could be replaced with ionizable amines, which resulted in analogues that showed improved potency and solubility. ${ }^{21-23,25}$ In contrast, studies suggested that the coumarin core serves only as a backbone to orient the benzamide and sugar side chains in the binding pocket. ${ }^{19}$ Subsequent studies determined that the coumarin ring could be replaced with other aromatic and heteroaromatic scaffolds without compromising activity. ${ }^{19,26}$

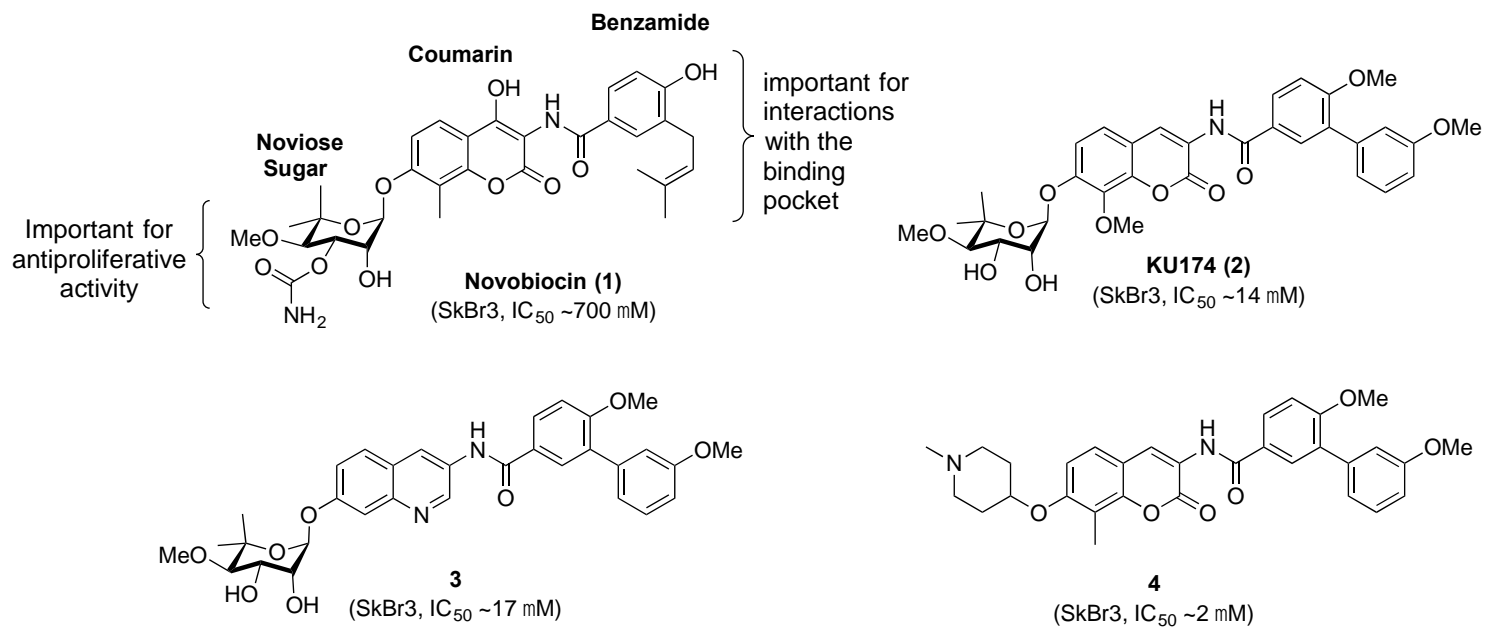

Figure 1. HSP90 C-terminal inhibitors.

More recently, it was demonstrated that the coumarin core could be replaced with a biaryl moiety, which resulted in increased anti-proliferative activity. ${ }^{26,}{ }^{27}$ As a flexible structure, the biphenyl ring system can adopt multiple conformations within the binding pocket and potentially, provide additional interactions with the protein. Indeed, structure-activity relationship (SAR) studies on the biaryl moiety led to the 
development of several efficacious inhibitors, such as KU820 (5) (Figure 2), which exhibited improved anti-proliferative activity. In addition, a library of quinoline derivatives that contain an alkylamino side chain at the 2-position were explored and led to identification of molecule, 6 (Figure 2), which showed sub-micromolar antiproliferative activity against several cancer cell lines. ${ }^{28}$ Importantly, the SAR studies suggested the potential for a previously unexplored hydrophilic region about the central core. Since incorporation of the alkylamino side chain onto the central core improved anti-proliferative activity by providing additional interactions with this region, it was proposed that placing this side chain onto the biphenyl core could also result in similar effects. Therefore, a series of alkylamino biphenylamides was synthesized and evaluated in an effort to develop more efficacious inhibitors.

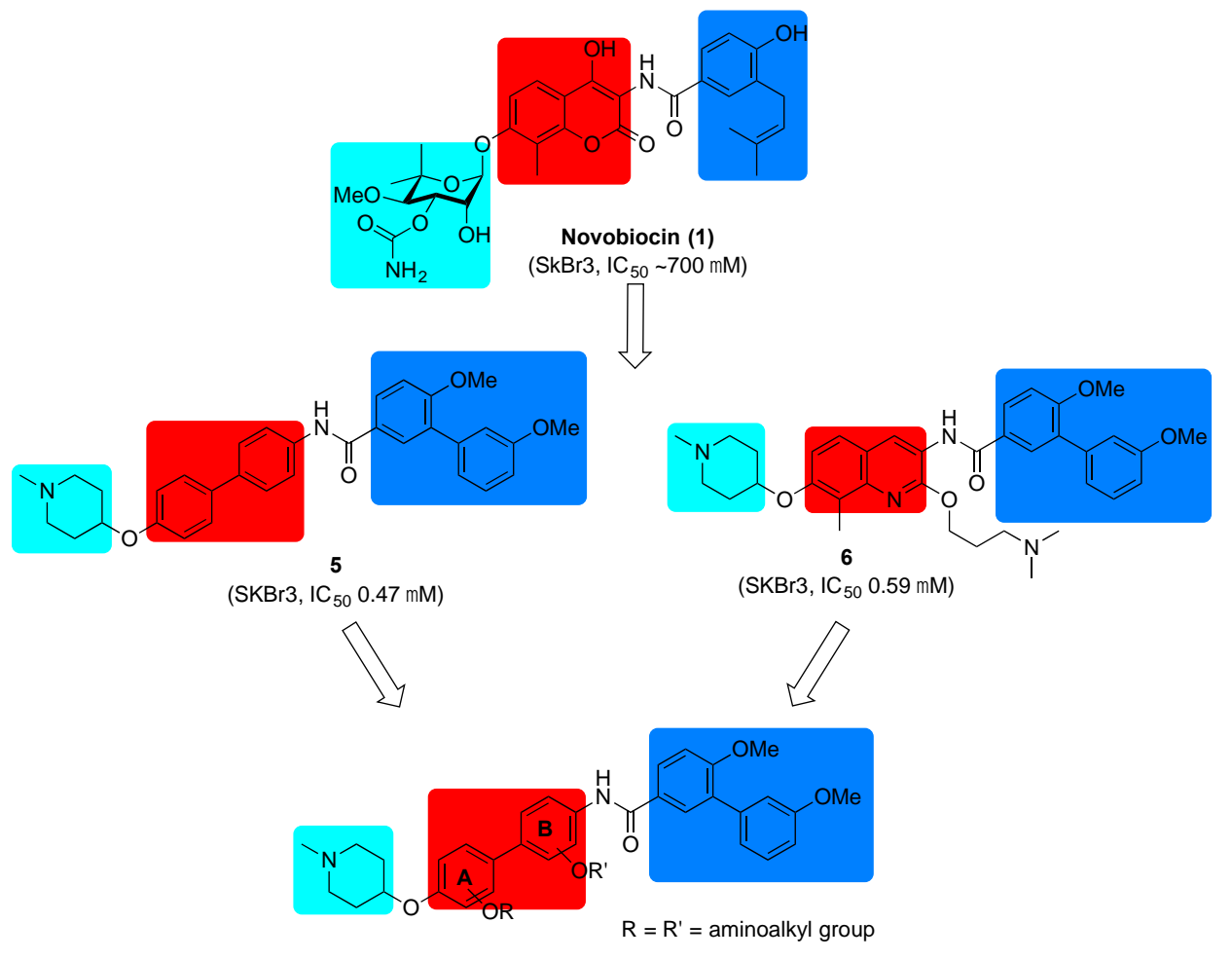

Proposed Alkylaminobiphenylamides

Figure 2. Rationale for proposed biphenylamide analogues. 


\section{Results and Discussion}

\subsection{Design of Alkylamino biphenylamides}

Early studies on novobiocin and related compounds revealed that the benzamide side chain and the sugar are important for anti-proliferative activity, while the central core appears to serve as an anchor to orient these appendages within the binding pocket. ${ }^{19,26}$ Therefore, a series of alkylamino biphenylamides (Figure 2) was designed to contain the optimized biaryl side chain and the sugar surrogate, $\mathrm{N}$-methyl4-piperidine, which are present in compound $\mathbf{5}$ in an effort to obtain additional interactions with the surrounding binding region as observed with 6 . The alkylamino side chain was incorporated into all four positions of the biphenyl core to identify the location that showed optimal anti-proliferative activity. Furthermore, prior studies on alkylamino quinolines suggested the propylamino linker was most efficacious. ${ }^{28}$ Since the biaryl core can adopt multiple conformations, the linker length was varied to contain either a 2-carbon or 3-carbon linker. Molecular overlay studies ${ }^{29}$ with compounds 5 and 6 (Figure 3), suggested the alkylamino side chain should be incorporated onto the B-ring of the biphenyl core. Therefore, the alkylamino biphenylamides with B-ring modifications were pursued first.
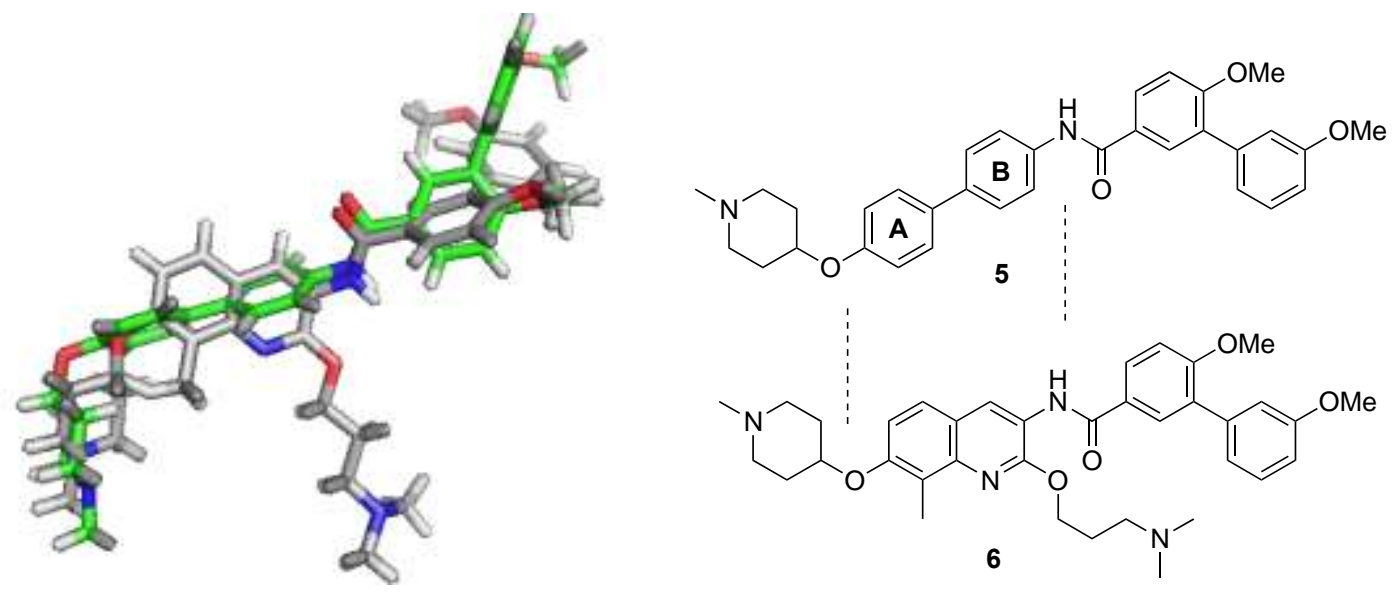

Figure 3. Molecular overlay of energy minimized compounds 5 (green) and 6 (grey). 


\subsection{Synthesis and biological evaluation of alkylamino biphenylamides}

As shown in Scheme 2, the preparation of biphenylamides containing B-ring modifications began by a Suzuki coupling between 4-hydoxyphenylbronic acid (7) and bromides $\mathbf{8 a - b}$, which were obtained through MOM-protection of the corresponding and commercially available phenols. Mitsunobu etherification of the nitrophenols (12ab) with 1-methyl-4-hydroxypiperidine (13) afforded nitro aromatics 14a-b, which were then reduced with $\mathrm{Pd} / \mathrm{C}$ under a hydrogen atmosphere to yield the anilines, 15a-b. Amide coupling of anilines $15 \mathbf{a}-\mathbf{b}$, with acid chloride $16 \mathbf{a}$ provided the corresponding amides, 17a-b, which were then MOM-deprotected and subjected to Mitsunobu etherification to give the final biphenylamides, 20a-d, in moderate yields.
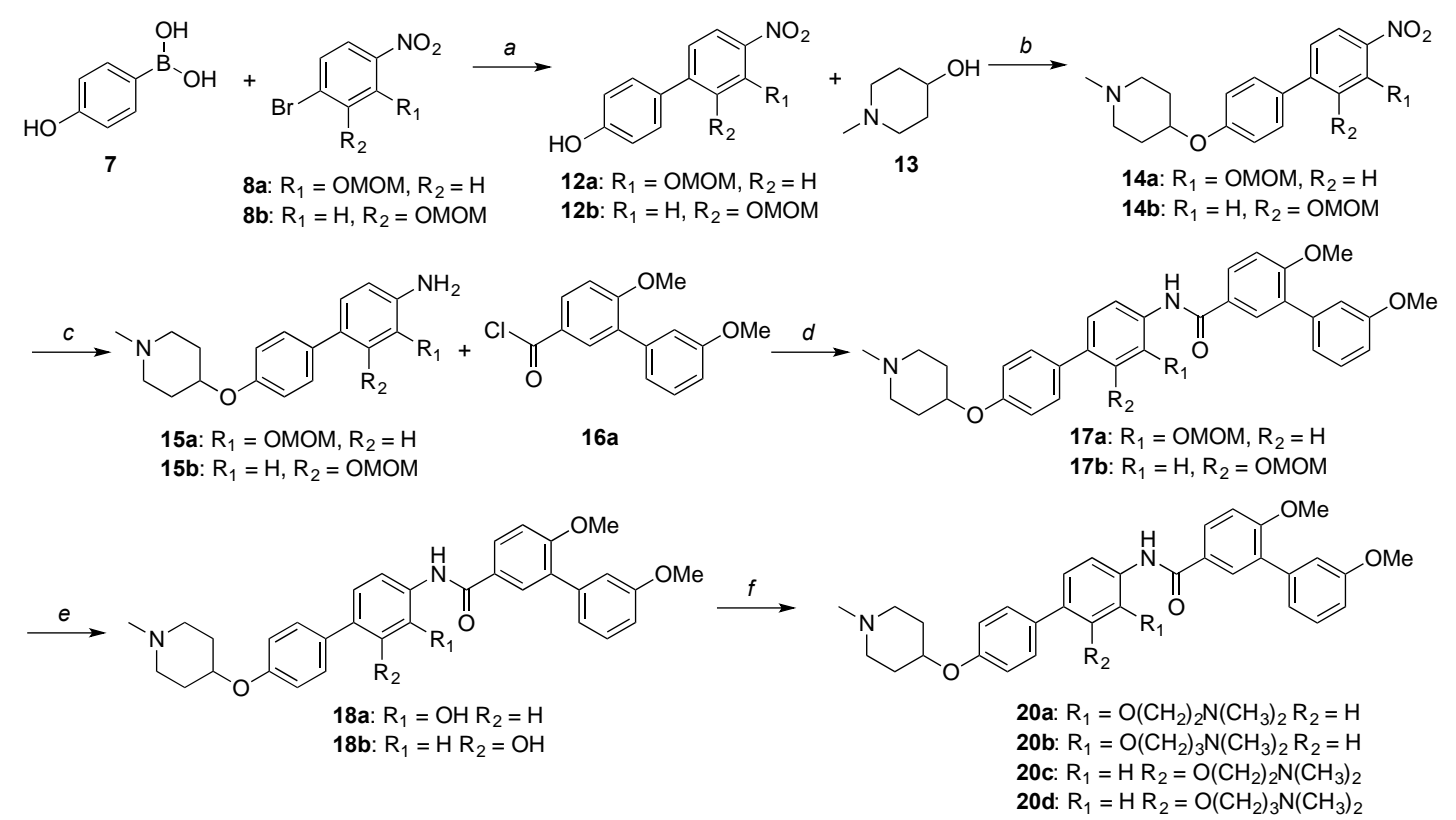

Reagaents and condtions: $a \mathrm{Pd}\left(\mathrm{PPh}_{3}\right)_{4}, 2 \mathrm{M} \mathrm{K}_{2} \mathrm{CO}_{3}, 1,4$-dioxane, $100{ }^{\circ} \mathrm{C}, 12 \mathrm{~h}, 58 \% \sim 62 \% ; b \mathrm{PPh}_{3}, \mathrm{DIAD}, \mathrm{THF}, 0^{\circ} \mathrm{C}$ to rt, $12 \mathrm{~h}, 56 \% \sim 60 \%$; c 10\% Pd/C, $\mathrm{H}_{2}, \mathrm{MeOH} / \mathrm{THF}, \mathrm{rt}, 12 \mathrm{~h}, \sim 100 \% ; d \mathrm{Et}_{3} \mathrm{~N}, \mathrm{DCM}, 0{ }^{\circ} \mathrm{C}$ to rt, $12 \mathrm{~h}, 68 \% \sim 88 \%$; e $p$-TSA, $\mathrm{MeOH}, \mathrm{rt}, 12 \mathrm{~h}, 77 \% \sim 82 \%$; $f$ Aminoalkyl alcohol, TMAD, $\mathrm{PBu}_{3}$, benzene, $80{ }^{\circ} \mathrm{C}, 12 \mathrm{~h}, 31 \% \sim 54 \%$.

Scheme 2: Synthesis of alkylamino biphenylamides with B-ring modifications.

Upon synthesis of these alkylamino biphenylamides, they were evaluated for anti-proliferative activity against SKBr3 (Her2 overexpressing breast cancer cells) and MCF-7 (estrogen receptor positive breast cancer cells) cell lines. As shown in table 1, 
biphenylamides that contain modifications to the B-ring manifested comparable activity to the unsubstituted analogue, 5. A phenol at either the C-2 or C-3 position of the Bring produced compounds that were less potent than the unsubstituted analogue (18a, $18 \mathrm{~b}$ vs 5 ). Surprisingly, introduction of alkylamino substituents at the 2-position of the B-ring (20a, 20b vs 18a) did not affect anti-proliferative activity. However, introduction of alkylamino substituents at the 3-position improved potency, as analogues (20c, 20d) exhibited $\sim 5$ fold greater anti-proliferative activity than $\mathbf{1 8 b}$. These data suggested that the alkylamino side chain is beneficial for anti-proliferative activity, however it may not provide optimal interactions with the surrounding region as was observed with the quinolines derivatives. These results encouraged investigation of alkylamino substitutions onto the A ring of the biphenylamide derivatives as well.

Table 1. Anti-proliferative activity of biphenylamides with B ring modifications.

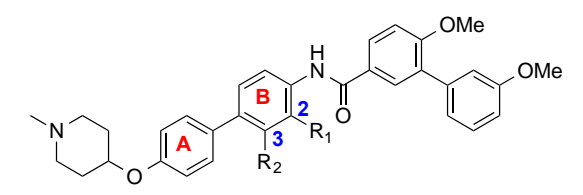

\begin{tabular}{|c|c|c|c|c|}
\hline Entry & $\mathbf{R}_{1}$ & $\mathbf{R}_{\mathbf{2}}$ & $\begin{array}{c}\text { SKBr3 } \\
\left(\mathrm{IC}_{50}, \mu \mathrm{M}\right)\end{array}$ & $\begin{array}{c}\text { MCF-7 } \\
\left(\mathrm{IC}_{50}, \boldsymbol{\mu M}\right)\end{array}$ \\
\hline 5 & $\mathrm{H}$ & $\mathrm{H}$ & $0.47 \pm 0.06^{a}$ & $0.71 \pm 0.02$ \\
\hline $18 a$ & $\mathrm{OH}$ & $\mathrm{H}$ & $0.91 \pm 0.02$ & $0.71 \pm 0.06$ \\
\hline $18 b$ & $\mathrm{H}$ & $\mathrm{OH}$ & $3.43 \pm 0.18$ & $1.80 \pm 0.11$ \\
\hline $20 a$ & ${ }_{\xi_{0}}{ }_{0}{ }^{1}{ }_{1}$ & $\mathrm{H}$ & $0.84 \pm 0.06$ & $0.81 \pm 0.18$ \\
\hline $20 \mathrm{~b}$ & $\mathrm{\xi}_{0}^{s} \frown \widehat{N}^{\prime}$ & $\mathrm{H}$ & $0.69 \pm 0.05$ & $0.75 \pm 0.02$ \\
\hline $20 \mathrm{c}$ & $\mathrm{H}$ & $\xi_{0}^{s} \sim^{1}$ & $0.65 \pm 0.01$ & $0.79 \pm 0.01$ \\
\hline 20d & $\mathrm{H}$ & $\hat{\xi}^{s} \bigcirc \widehat{N}^{\prime}$ & $0.55 \pm 0.05$ & $0.67 \pm 0.02$ \\
\hline
\end{tabular}

${ }^{a}$ Values represent mean \pm standard deviation for at least two separate experiments performed in triplicate. 
As shown in Scheme 3, a series of biphenyl derivatives containing a modified A-ring was synthesized for comparison with B-ring modifications. Synthesis of biphenyl derivatives was initiated via a Suzuki coupling of nitrophenylboronic acid (11) with previously reported bromophenols, ${ }^{30} \mathbf{1 0 a - b}$, to afford nitrophenols $\mathbf{1 2 c - d}$, which then underwent Mitsunobu etherification with 1-methyl-4-hydroxypiperidine (13) to give the corresponding nitro aromatics, 14c-d. Reduction of 14c-d, followed by amide coupling with acid chloride 16a afforded the amides 17c-d. Acid-catalyzed MOM-deprotection of 17c-d, followed by Mitsunobu etherification gave the desired biphenylamides (20e-f) in modest to low yields.

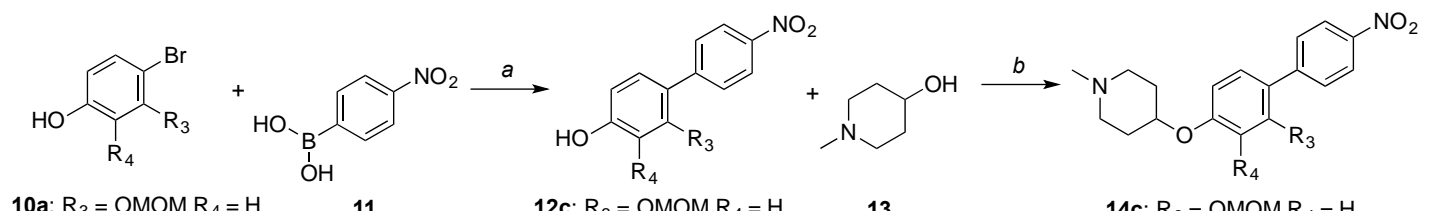

10a: $\mathrm{R}_{3}=\mathrm{OMOM} \mathrm{R}_{4}=\mathrm{H}$ 10b: $\mathrm{R}_{3}=\mathrm{HR}_{4}=\mathrm{OMOM}$

12c: $R_{3}=\mathrm{OMOM} \mathrm{R}_{4}=\mathrm{H}$ 12d: $R_{3}=\mathrm{H} \mathrm{R}_{4}=\mathrm{OMOM}$
13 14c: $R_{3}=O M O M R_{4}=H$ 14d: $\mathrm{R}_{3}=\mathrm{HR}_{4}=\mathrm{OMOM}$
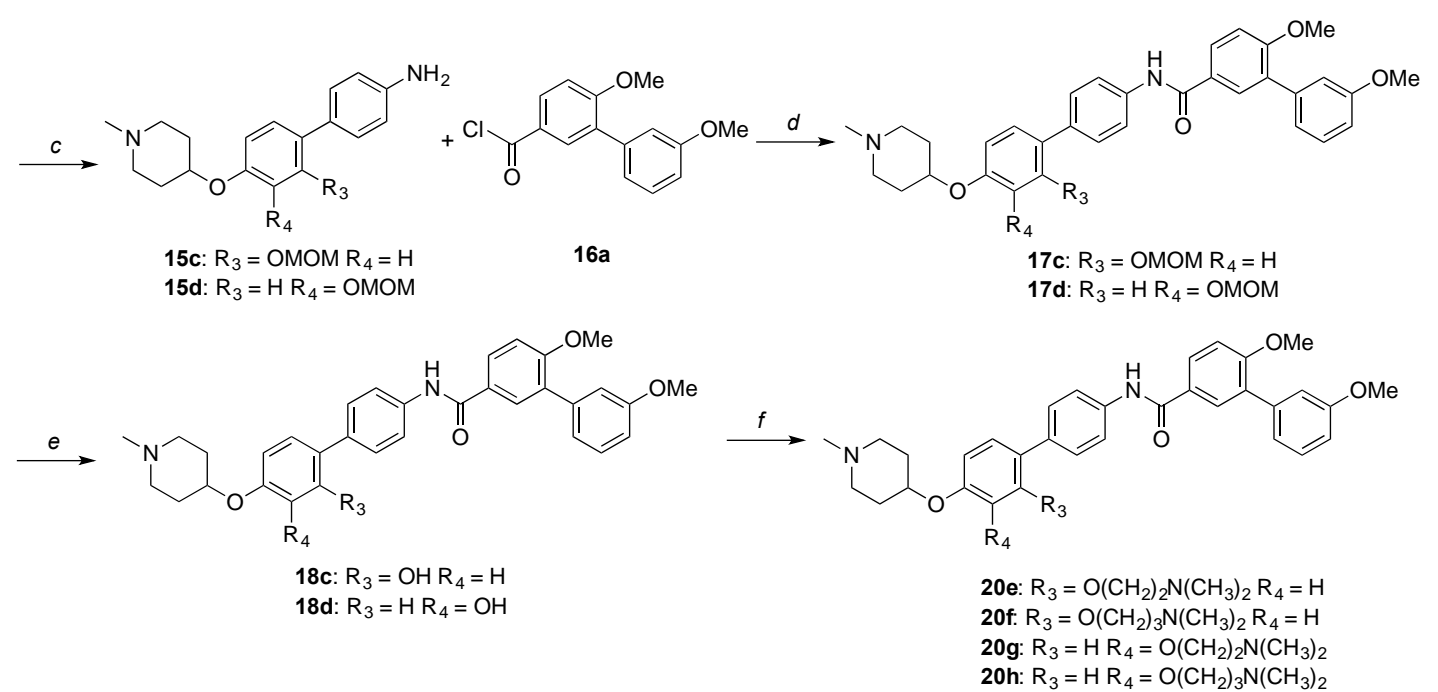

Reagaents and condtions: a $\mathrm{Pd}\left(\mathrm{PPh}_{3}\right)_{4}, 2 \mathrm{M} \mathrm{Na}{ }_{2} \mathrm{CO}_{3}$, toluene/EtOH, $120{ }^{\circ} \mathrm{C}, 12 \mathrm{~h}, 60 \% \sim 73 \% ; c \mathrm{PPh}_{3}, \mathrm{DIAD}, \mathrm{THF}, 0^{\circ} \mathrm{C}$ to rt, 12 h, 89\% 92\%; d 10\% Pd/C, $\mathrm{H}_{2} \mathrm{CH}_{3} \mathrm{COOH}, \mathrm{MeOH} / \mathrm{THF}$, rt, $12 \mathrm{~h}, \sim 100 \%$; e Et ${ }_{3} \mathrm{~N}, \mathrm{THF}, 0{ }^{\circ} \mathrm{C}$ to rt, $12 \mathrm{~h}, 65 \% \sim 67 \%$; $f 2 \mathrm{~N} \mathrm{HCl}, \mathrm{MeOH}, \mathrm{rt}, 12 \mathrm{~h}, 82 \% \sim 87 \%$; g Aminoalkyl alcohol, TMAD, $\mathrm{PBu}_{3}$, benzene, $80^{\circ} \mathrm{C}, 12 \mathrm{~h}, 30 \% \sim 45 \%$.

Scheme 3: Synthesis of alkylamino biphenylamides with A-ring modifications.

Upon their preparation, the biphenylamides with modifications to the A-ring were evaluated for their anti-proliferative activity against $\mathrm{SKBr} 3$ and $\mathrm{MCF}-7$ breast cancer cell lines (Table-2). In general, biphenylamides containing modifications to the 
A-ring were more potent than the biphenyl derivatives with B-ring modifications. It appears that substitution on the A-ring of the biphenyl core (18c, 18d, 17c or $17 \mathbf{d}$ vs $\mathbf{6})$ is less favorable, which may be explained by suboptimal conformations of the biphenyl linker that leads to diminished interactions with the binding pocket. Similar to the trend observed with the B-ring modifications, incorporation of the alkylamino side chain onto the A-ring improved anti-proliferative activity, as analogues (20e-h) were $5 \sim 10$ fold more potent than $\mathbf{1 8 c}$ or $\mathbf{1 8 d}$. The data suggests that incorporation of an alkylamino side chain onto the 3'-position of the A-ring results in compounds that show good antiproliferative activity (20e, 20f vs $20 \mathrm{a}-\mathbf{d}, \mathbf{2 0 g}, \mathbf{2 0 h}$ ). Furthermore, analogues containing a 3-carbon linker exhibited slightly improved activity over the corresponding 2-carbon tethered biphenylamide (20f vs $20 \mathrm{e}$ ).

Table 2. Anti-proliferative activity of biphenylamides with A ring modifications.

\begin{tabular}{|c|c|c|c|c|}
\hline Entry & $\mathbf{R}_{3}$ & $\mathbf{R}_{\mathbf{4}}$ & $\begin{array}{c}\text { SKBr3 } \\
\left(\mathrm{IC}_{50}, \mu \mathrm{M}\right)\end{array}$ & $\begin{array}{c}\text { MCF-7 } \\
\left(\mathrm{IC}_{50}, \mu \mathrm{M}\right)\end{array}$ \\
\hline $18 c$ & $\mathrm{OH}$ & $\mathrm{H}$ & $3.55 \pm 0.41$ & $4.07 \pm 0.23$ \\
\hline $18 d$ & $\mathrm{H}$ & $\mathrm{OH}$ & $1.56 \pm 0.40$ & $1.22 \pm 0.20$ \\
\hline $17 c$ & $\xi^{5} \widehat{O}_{0}$ & $\mathrm{H}$ & $1.14 \pm 0.33$ & $1.38 \pm 0.32$ \\
\hline $20 e$ & $\xi^{\xi_{0}} \Upsilon^{1} N_{1}$ & $\mathrm{H}$ & $0.39 \pm 0.03$ & $1.04 \pm 0.20$ \\
\hline $20 f$ & $\xi^{s} 0 ح \mathrm{~N}^{\prime}$ & $\mathrm{H}$ & $0.34 \pm 0.02$ & $0.84 \pm 0.04$ \\
\hline $17 d$ & $\mathrm{H}$ & $\xi^{\xi_{0}} \widehat{0}^{-}$ & $0.82 \pm 0.05$ & $0.99 \pm 0.03$ \\
\hline $20 \mathrm{~g}$ & $\mathrm{H}$ & $\xi_{0}^{\xi_{0}} \sim^{1}$ & $0.40 \pm 0.06$ & $0.70 \pm 0.01$ \\
\hline $20 \mathrm{~h}$ & $\mathrm{H}$ & $\xi_{0}^{s} \bigcirc{ }_{N^{\prime}}$ & $0.75 \pm 0.01$ & $1.05 \pm 0.30$ \\
\hline
\end{tabular}

Overall, preliminary structure-activity relationships indicate that the propylamino side chain is important for enhanced anti-proliferative activity. In addition, the 3' 
position of the A-ring represents the best location for further investigation of the side chain. To investigate the optimal linker length and substituent effect, a concise library of the biphenylamides containing rigid, hydrophobic and non-ionizable moieties was synthesized as shown in scheme 4.
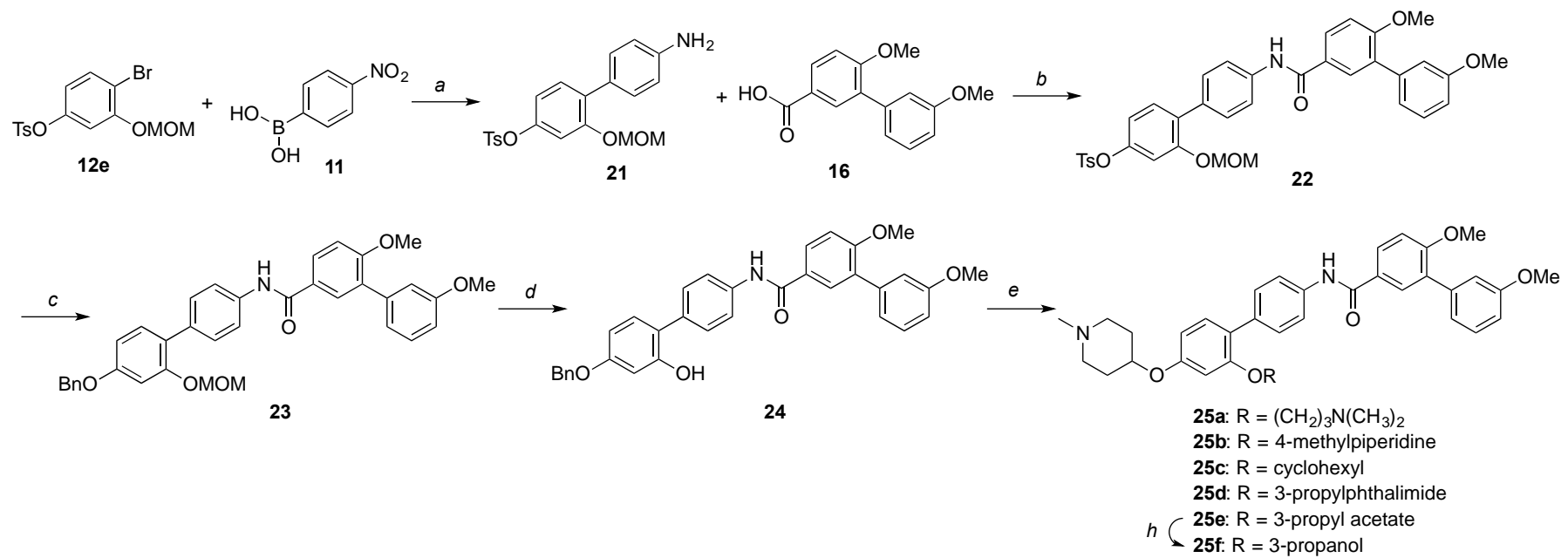

Reagaents and condtions: a i. $\mathrm{Pd}\left(\mathrm{PPh}_{3}\right)_{4}, 2 \mathrm{M} \mathrm{Na}_{2} \mathrm{CO}_{3}$, toluene/EtOH, $120{ }^{\circ} \mathrm{C}, 12 \mathrm{~h}, 79 \%$, ii. $10 \% \mathrm{Pd} / \mathrm{C}, \mathrm{H}_{2}, \mathrm{THF} / \mathrm{MeOH}, \mathrm{rt}, 12 \mathrm{~h}, \sim 100 \%$; $b \mathrm{EDCl} \mathrm{HCl}, \mathrm{HOBt}, \mathrm{Et}_{3} \mathrm{~N}, \mathrm{DCM}, 0^{\circ} \mathrm{C}$ to rt, $12 \mathrm{~h}, 68 \%$; $c$ i. $3.2 \mathrm{~N} \mathrm{KOH}, \mathrm{EtOH}, 90^{\circ} \mathrm{C}, 3 \mathrm{~h}, 68 \%$, ii. $\mathrm{BnBr}, \mathrm{K}_{2} \mathrm{CO}_{3}$, acetone, $65{ }^{\circ} \mathrm{C}, 12,85 \%$; $d 2 \mathrm{~N} \mathrm{HCl}, \mathrm{MeOH}, \mathrm{rt}, 12 \mathrm{~h}, 85 \%$; e i. TMAD, $\mathrm{PBu}_{3}$, benzene, $80^{\circ} \mathrm{C}, 12 \mathrm{~h}, 56 \%$ or R-Cl, $\mathrm{K}_{2} \mathrm{CO}_{3}, \mathrm{DMF}, 0{ }^{\circ} \mathrm{C}$ to rt, $12 \mathrm{~h}, 50 \% \sim 70 \%$; ii. $10 \% \mathrm{Pd} / \mathrm{C}, \mathrm{H}_{2}, \mathrm{MeOH} / \mathrm{THF}, \mathrm{rt}, 12 \mathrm{~h}, \sim 100 \%$; iii. DIAD, $\mathrm{PPh}_{3}, \mathrm{THF}, 0^{\circ} \mathrm{C}$ to rt, $12 \mathrm{~h}, 23 \% \sim 50 \% ; h \mathrm{~K}_{2} \mathrm{CO}_{3}, \mathrm{MeOH}, \mathrm{rt}, 4 \mathrm{~h}, 65 \%$.

Scheme 4: Synthesis of biphenylamides with varied alkyl side chains.

The anti-proliferation activity exhibited by these analogues is reported in Table 3. The results indicated that the 3-carbon linker is optimal, as further homologation of the linker length resulted in reduced activity (25a vs 20f). Incorporation of a cyclic amine decreased anti-proliferative activity (25b), suggesting the need for a flexible substituent. In addition, introduction of steric bulk (25c) diminished activity, indicating there is limited space in the surrounding binding pocket. Incorporation of the aliphatic substituent produced a less active compound (25d vs 20f), which suggests that improved anti-proliferative activity may result from either hydrogen-bonding or ionic interactions with the binding region. Surprisingly, incorporation of both a hydrogenbond donor and/or acceptor $(25 e, 25 f)$ reduced activity, indicating that the charged ammonium group is important to increase anti-proliferative activity. 
Table 3. Anti-proliferative activity of biphenylamides.

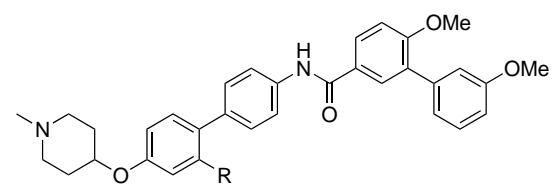

\begin{tabular}{|c|c|c|c|}
\hline Entry & $\mathbf{R}$ & $\begin{array}{c}\text { SKBr3 } \\
\left(I_{50}, \mu M\right)\end{array}$ & $\begin{array}{c}\text { MCF-7 } \\
\left(\mathrm{IC}_{50}, \mu \mathrm{M}\right)\end{array}$ \\
\hline $20 f$ & - & $0.34 \pm 0.02$ & $0.84 \pm 0.04$ \\
\hline $25 a$ & $\xi^{s} 0$ & $1.27 \pm 0.32$ & $1.12 \pm 0.13$ \\
\hline $25 b$ & & $1.16 \pm 0.98$ & $2.54 \pm 0.65$ \\
\hline $25 c$ & & $3.13 \pm 0.98$ & $1.43 \pm 0.27$ \\
\hline $25 d$ & & $3.24 \pm 0.04$ & $2.36 \pm 0.02$ \\
\hline $25 e$ & & $1.96 \pm 0.26$ & $2.49 \pm 0.41$ \\
\hline $2 e f$ & క50 & $3.87 \pm 0.28$ & $3.11 \pm 0.21$ \\
\hline
\end{tabular}

The antiproliferative activity produced by these biphenylamides was confirmed to result from Hsp90 inhibition by a luciferase-refolding assay. As shown in Figure 4A, 20e and 20f inhibited the Hsp90-dependent refolding of thermally denatured luciferase, confirming that these analogues exhibit their cellular activity through modulation of the Hsp90 protein folding machinery. Western blot analysis was performed with MCF-7 cell lysates treated with the most active compound, 20f to provide additional evidence of Hsp90 inhibition. As shown in figure 4B, incubation with 20 induced the degradation of Hsp90-dependent client proteins, Her2, Raf-1, and Akt in a concentration-dependent manner, without affecting actin levels. In addition, Hsp90 levels remained constant at all concentrations, which is a hallmark resulting from Hsp90 C-terminal inhibition. 
A.

\section{Luciferase Assay}

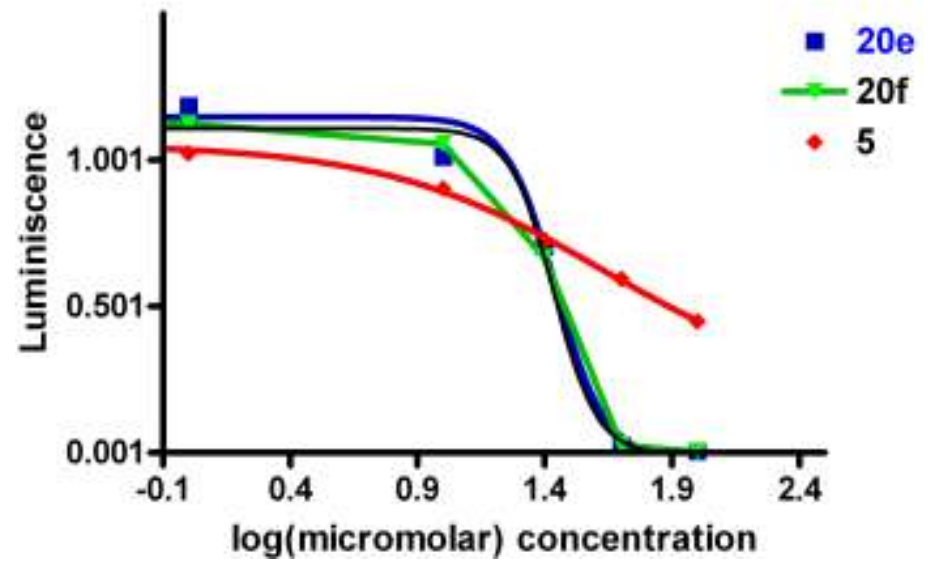

B.

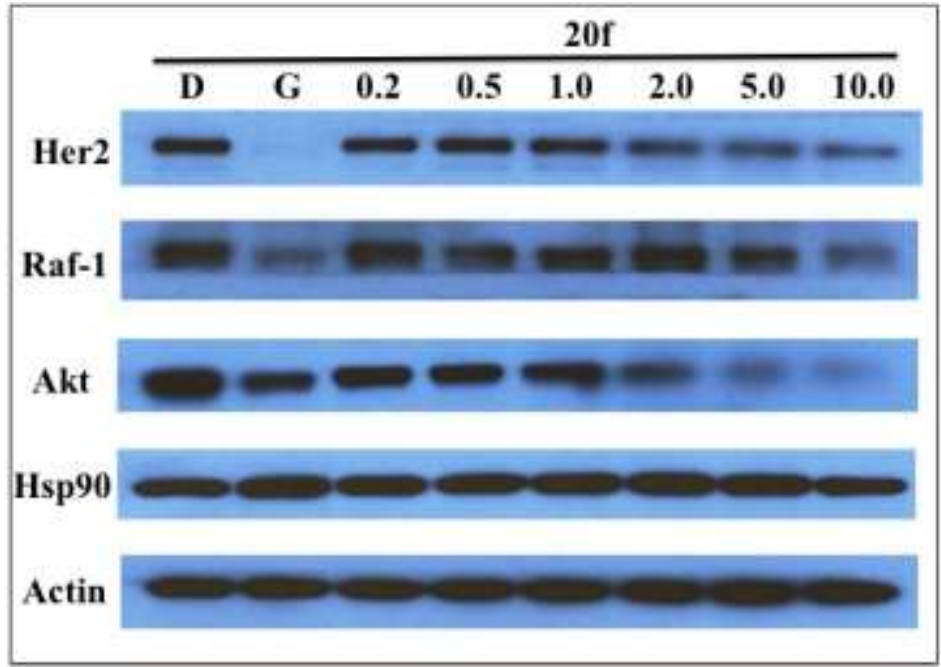

Figure 4A. Luciferase refolding activity of Hsp90 in PC3- MM2 cells with vehicle (DMSO), 20e, 20f and 5 (positive control). The concentrations used were $0.1-100 \mu \mathrm{M}$. B. Western blot analyses of Hsp90-dependent client proteins (Her2, Raf-1 and ER) using lysate from MCF-7 breast cancer cells treated with 20 for $24 \mathrm{~h}$. Concentrations (in $\mu \mathrm{M}$ ) were indicated above each lane. Geldanamycin (G, $0.5 \mu \mathrm{M})$ and dimethylsulfoxide (D, 100\%) were employed as positive and negative controls respectively.

\section{Conclusions}

In summary, a series of alkylamino biphenylamides was designed, synthesized and evaluated for anti-proliferative activity against MCF-7 and SKBr3 breast cancer cell lines. The incorporation of an alkylamino side chain onto the biphenyl core resulted in 
compounds that manifest sub-micromolar to mid-nanomolar inhibitory activity. Both, luciferase refolding assays and Western blot analyses confirmed these compounds exhibit their anti-proliferative activity through Hsp90 inhibition. SAR studies revealed that amines attached to a three-carbon linker gave the most potent biphenylamides analogues.

\section{Experimental section}

4.1 Anti-proliferation assays. Cells were maintained in a 1:1 mixture of Advanced DMEM/F12 (Gibco) supplemented with non-essential amino acids, L-glutamine (2 $\mathrm{mM})$, streptomycin $(500 \mu \mathrm{g} / \mathrm{mL})$, penicillin $(100$ units $/ \mathrm{mL})$, and $10 \%$ FBS. Cells were grown to confluence in a humidified atmosphere $\left(37^{\circ} \mathrm{C}, 5 \% \mathrm{CO}_{2}\right)$, seeded (2000/well, $100 \mu \mathrm{L})$ in 96-well plates, and allowed to attach overnight. Compound or GDA at varying concentrations in DMSO (1\% DMSO final concentration) was added, and cells were returned to the incubator for $72 \mathrm{~h}$. At $72 \mathrm{~h}$, the number of viable cells was determined using an MTS/PMS cell proliferation kit (Promega) per the manufacturer's instructions. Cells incubated in 1\% DMSO were used at $100 \%$ proliferation, and values were adjusted accordingly. $I_{50}$ values were calculated from separate experiments performed in triplicate using GraphPad Prism.

4.2 Western blot Analyses. MCF-7 cells were cultured as described above and treated with various concentrations of drug, GDA in DMSO (1\% DMSO final concentration), or vehicle (DMSO) for $24 \mathrm{~h}$. Cells were harvested in cold PBS and lysed in RIPA lysis buffer containing $1 \mathrm{mM}$ PMSF, $2 \mathrm{mM}$ sodium orthovanadate, and protease inhibitors on ice for $1 \mathrm{~h}$. Lysates were clarified at $14000 \mathrm{~g}$ for 10 min at $4^{\circ} \mathrm{C}$. Protein concentrations were determined using the Pierce BCA protein assay kit per the manufacturer's instructions. Equal amounts of protein $(20 \mu \mathrm{g})$ were electrophoresed under reducing conditions, transferred to a nitrocellulose membrane, and immunoblotted with the corresponding specific antibodies. Membranes were incubated with an appropriate horseradish peroxidase-labeled secondary antibody, developed with a chemiluminescent substrate, and visualized.

\section{Acknowledgment}

The authors gratefully acknowledge support of this project by the $\mathrm{NIH} / \mathrm{NCl}$ (CA120458). The NMR support for this project was provided by NSF (9512331). The authors are greatly thankful to Frontier Scientific, Inc. for providing high quality boronic acids for this project. 


\section{Reference}

1. Taipale, M.; Jarosz, D. F.; Lindquist, S. Nat. Rev. Mol. Cell Biol. 2010, 11, 515-528.

2. Taipale, M.; Krykbaeva, I.; Koeva, M.; Kayatekin, C.; Westover, Kenneth D.; Karras, Georgios I.; Lindquist, S. Cell 2012, 150, 987-1001.

3. Hanahan, D.; Weinberg, R. A. Cell 2000, 100, 57-70.

4. Hanahan, D.; Weinberg, Robert A. Cell 2011, 144, 646-674.

5. Garg, G.; Khandelwal, A.; Blagg, B. S. Adv. Cancer Re.s 2016, 129, 51-88.

6. Dai, C.; Dai, S.; Cao, J. J. Cell. Physio. 2012, 227, 2982-2987.

7. Stephanie, C. B.; Joseph, A. B.; Brian, S. J. B. Curr. Cancer Drug Targets 2007, 7, 369-388.

8. Chaudhury, S.; Welch, T. R.; Blagg, B. S. J. ChemMedChem 2006, 1, 1331-1340.

9. Bishop, S. C.; Burlison, J. A.; Blagg, B. S. Curr. Cancer Drug Targets 2007, 7, 369388.

10. Neckers, L.; Workman, P. Hsp90 Clin. Cancer Res. 2012, 18, 64-76.

11. Whitesell, L.; Lindquist, S. L. Nat. Rev. Cancer 2005, 5, 761-772.

12. Brandt, G. E.; Blagg, B. S. Curr. Top. Med. Chem. 2009, 9, 1447-1461.

13. Marcu, M. G.; Schulte, T. W.; Neckers, L. J. Natl. Cancer Inst. 2000, 92, 242-248.

14. Marcu, M. G.; Chadli, A.; Bouhouche, I.; Catelli, M.; Neckers, L. M. J. Biol. Chem. 2000, 275, 37181-37186.

15. Donnelly, A.; Blagg, B. S. Curr. Med. Chem. 2008, 15, 2702-2717.

16. Yu, X. M.; Shen, G.; Neckers, L.; Blake, H.; Holzbeierlein, J.; Cronk, B.; Blagg, B. S. J. J. Am. Chem. Soc. 2005, 127, 12778-12779.

17. Burlison, J. A.; Neckers, L.; Smith, A. B.; Maxwell, A.; Blagg, B. S. J. J. Am. Chem. Soc. 2006, 128, 15529-15536.

18. Burlison, J. A.; Avila, C.; Vielhauer, G.; Lubbers, D. J.; Holzbeierlein, J.; Blagg, B. S. J. J. Org. Chem. 2008, 73, 2130-2137.

19. Donnelly, A. C.; Mays, J. R.; Burlison, J. A.; Nelson, J. T.; Vielhauer, G.; Holzbeierlein, J.; Blagg, B. S. J. J. Org. Chem 2008, 73, 8901-8920.

20. Eskew, J. D.; Sadikot, T.; Morales, P.; Duren, A.; Dunwiddie, I.; Swink, M.; Zhang, X.; Hembruff, S.; Donnelly, A.; Rajewski, R. A.; Blagg, B. S.; Manjarrez, J. R.; Matts, R. L.; Holzbeierlein, J. M.; Vielhauer, G. A. BMC Cancer 2011, 11, 468.

21. Zhao, H.; Donnelly, A. C.; Kusuma, B. R.; Brandt, G. E. L.; Brown, D.; Rajewski, R. A.; Vielhauer, G.; Holzbeierlein, J.; Cohen, M. S.; Blagg, B. S. J. J. Med. Chem. 2011, 54, 3839-3853.

22. Zhao, H.; Blagg, B. S. J. Bioorg. Med. Chem. Lett. 2013, 23, 552-557.

23. Garg, G.; Zhao, H.; Blagg, B. S. J. ACS Med. Chem. Lett. 2014.

24. Ghosh, S.; Liu, Y.; Garg, G.; Anyika, M.; McPherson, N. T.; Ma, J.; Dobrowsky, R. T.; Blagg, B. S. J. ACS Med. Chem. Lett. 2016, 7, 813-818.

25. Zhao, H.; Reddy Kusuma, B.; Blagg, B. S. J. ACS Med. Chem. Lett. 2010, 1, 311315.

26. Zhao, H.; Garg, G.; Zhao, J.; Moroni, E.; Girgis, A.; Franco, L. S.; Singh, S.; Colombo, G.; Blagg, B. S. J. Eur. J. Med. Chem. 2015, 89, 442-466. 
27. Zhao, H.; Moroni, E.; Colombo, G.; Blagg, B. S. J. ACS Med. Chem. Lett 2013, 5, 84-88.

28. Kusuma, B. R.; Khandelwal, A.; Gu, W.; Brown, D.; Liu, W.; Vielhauer, G.; Holzbeierlein, J.; Blagg, B. S. J. Bioorg. Med. Chem. Lett 2014, 22, 1441-1449.

29. Matts, R. L.; Dixit, A.; Peterson, L. B.; Sun, L.; Voruganti, S.; Kalyanaraman, P.; Hartson, S. D.; Verkhivker, G. M.; Blagg, B. S. J. ACS Chem. Biol. 2011, 6, 800-807.

30. Shimomura, K.; Ikai, T.; Kanoh, S.; Yashima, E.; Maeda, K. Nat. Chem. 2014, 6, 429-434. 
Figure 1. HSP90 C-terminal inhibitors.

Figure 2. Rationale for proposed biphenylamide analogues.

Figure 3. Molecular overlay of energy minimized compounds 5 (green) and 6 (grey).

Figure 4A. Luciferase refolding activity of Hsp90 in PC3- MM2 cells with vehicle (DMSO), 20e, 20f and 5 (positive control). The concentrations used were $0.1-100 \mu \mathrm{M}$. B. Western blot analyses of Hsp90-dependent client proteins (Her2, Raf-1 and ER) using lysate from MCF-7 breast cancer cells treated with 20 for $24 \mathrm{~h}$. Concentrations (in $\mu \mathrm{M})$ were indicated above each lane. Geldanamycin (G, $0.5 \mu \mathrm{M})$ and dimethylsulfoxide (D, 100\%) were employed as positive and negative controls respectively. 


\section{Graphical Abstract:}
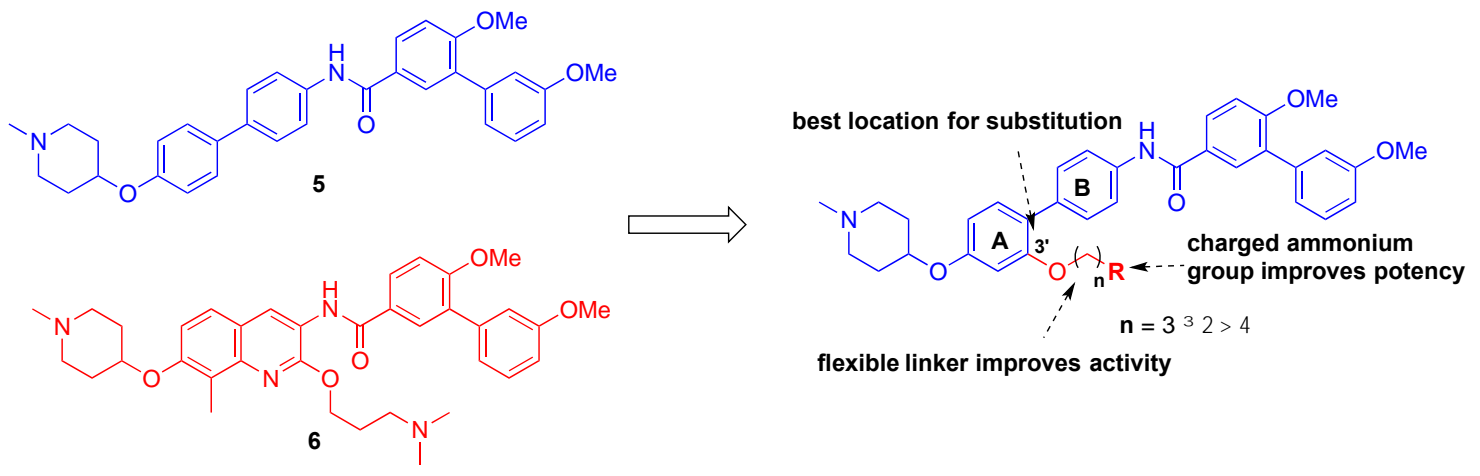

flexible linker improves activity 